William E. Fantegrossi • Thomas Ullrich

Kenner C. Rice · James H. Woods · Gail Winger

\title{
3,4-Methylenedioxymethamphetamine (MDMA, "ecstasy") and its stereoisomers as reinforcers in rhesus monkeys: serotonergic involvement
}

Received: 10 August 2001 / Accepted: 12 January 2002 / Published online: 19 April 2002

(C) Springer-Verlag 2002

\begin{abstract}
Rationale: The reinforcing effects of MDMA and its enantiomers have not been extensively characterized in laboratory animals. Objectives: To investigate whether MDMA and its stereoisomers would be selfadministered intravenously by rhesus monkeys (Macaca mulatta), and to assess the effects of serotonin $_{2}$ receptor $^{2}$ antagonists on MDMA-maintained responding. Methods: Four adult male rhesus monkeys were maintained on a fixed ratio 10 , time-out 60 -s schedule for $0.01 \mathrm{mg} / \mathrm{kg}$ cocaine or saline injections. Racemic MDMA and its stereoisomers, and racemic methamphetamine were periodically substituted for cocaine or saline. In subsequent antagonist experiments, five adult rhesus monkeys (three male, two female) were maintained on a multiple dose fixed ratio 30, time-out 45-s schedule for cocaine or saline injections. Racemic MDMA and its enantiomers were periodically substituted for cocaine or saline, with or without a pre-session injection of the $\operatorname{serotonin}_{2}$ receptor antagonists ketanserin or MDL100907. Results: In the initial self-administration experiments, MDMA and its stereoisomers generated "inverted U"-shaped self-administration curves across the dose range tested. Racemic MDMA doses between 0.01 and $0.1 \mathrm{mg} / \mathrm{kg}$ per injection, S(+)-MDMA doses between 0.003 and $0.1 \mathrm{mg} / \mathrm{kg}$ per injection, and R(-)-MDMA doses between 0.01 and $0.1 \mathrm{mg} / \mathrm{kg}$ per injection engendered more responding than saline; however, no dose of any form of MDMA maintained as much behavior as cocaine or methamphetamine. In subsequent antagonist experiments, pretreatments with 0.1 or $0.3 \mathrm{mg} / \mathrm{kg}$ ketanserin or
\end{abstract}

W.E. Fantegrossi · J.H. Woods $(\bullet)$

Department of Psychology (Biopsychology Program),

University of Michigan, Ann Arbor, MI 48109-1109, USA

Fax: +1-734-7647118

G. Winger

Department of Pharmacology, University of Michigan,

Medical School, 1301 MSRB III, Ann Arbor, MI 48109-0632, USA

T. Ullrich · K.C. Rice

Laboratory of Medicinal Chemistry, NIDDK,

National Institutes of Health, Building 8,

Room B1-21, Bethesda, MD 20892, USA
MDL100907 attenuated responding for S(+)-MDMA, and completely abolished responding for R(-)-MDMA, but did not affect cocaine-maintained behavior. Conclusions: MDMA and its stereoisomers serve as reinforcers in rhesus monkeys. We suggest that stimulation of $5-\mathrm{HT}_{2 \mathrm{~A}}$ receptors is integral to the reinforcing effects of MDMA.

Keywords MDMA - Self-administration .

Serotonin antagonist $\cdot$ Rhesus monkey $\cdot$ Amphetamine

\section{Introduction}

3,4-Methylenedioxymethamphetamine (MDMA, "ecstasy") is a ring-substituted phenethylamine that shares structural features with amphetamine-like stimulants as well as mescaline-like hallucinogens. MDMA exerts preferential effects on central serotonin (5-HT) systems, including blockade of reuptake mechanisms and stimulation of 5-HT release (e.g. Rudnick and Wall 1991.) Ex vivo radioligand binding experiments indicate that racemic MDMA has high affinity for 5-HT transporters and lesser affinity for $5-\mathrm{HT}_{2}$ serotonin receptors (Battaglia et al. 1988a). Experiments with the enantiomers, however, reveal that $\mathrm{R}(-)$-MDMA has higher affinity for postsynaptic 5-HT receptors than does S(+)-MDMA, and that S(+)-MDMA has higher affinity for 5-HT transporters than does R(-)-MDMA (Battaglia and De Souza 1989).

A $1.5 \mathrm{mg} / \mathrm{kg}$ dose of MDMA has been shown to produce numerous subjective effects in the human, including an affective state of positive mood, moderate derealization, heightened sensory awareness, and increased psychomotor drive (Liechti et al. 2000a). This cluster of subjective effects differs from that produced by either traditional hallucinogens or psychostimulants (Nichols and Oberlender 1990). MDMA remains a widespread drug of abuse worldwide, and may be enjoying a peak in recreational popularity due to the spreading prevalence of the "rave" counterculture with which the drug is closely allied (Brown et al. 1995). 
Studies in rodents (Battaglia et al. 1988b) and primates (Ricaurte et al. 1992) have demonstrated long-lasting reductions in 5-HT and its metabolite 5-hydroxyindoleacetic acid (5-HIAA), as well as other neurochemical changes associated with destruction of central 5-HT terminals (Battaglia et al. 1987; Hatzidimitriou et al. 1999), following both acute and chronic MDMA administration. Concern over increasing recreational use of MDMA and the concomitant neurotoxic effects that may accompany such use in humans prompted the Drug Enforcement Agency to invoke its emergency scheduling powers, placing MDMA in Schedule 1 under the Controlled Substances Act in 1985.

Despite the widespread recreational use of the compound, the reinforcing effects of MDMA have not been extensively characterized in laboratory animals. MDMA has, however, been shown to elicit conditioned place preference (Bilsky et al. 1991; Marona-Lewicka et al. 1996) and to decrease the threshold for rewarding electrical stimulation of the brain (Hubner et al. 1987) in rats. Finally, although racemic MDMA has twice been shown to act as a reinforcer in intravenous selfadministration paradigms in primates (Beardsley et al. 1986; Lamb and Griffiths 1987), to our knowledge, the reinforcing effects of the stereoisomers have not been previously assessed.

The stimulus properties of the MDMA enantiomers have, however, been intensively investigated, and the drug discrimination literature indicates that these compounds may have distinct subjective effects. The discriminative stimulus profile of MDMA is complex, and differences in subject species, conditioning histories, discrimination protocols, and training doses used across these studies have often led to conflicting results. However, a generalization of these findings seems to indicate that the discriminable cue of S(+)-MDMA is more likely to be reported as dopaminergic than serotonergic, whereas the stimulus properties of $\mathrm{R}(-)$-MDMA are more likely to be reported as serotonergic than dopaminergic (Glennon et al. 1988; Baker et al. 1995; Baker and Taylor 1997.) It was therefore of interest to determine whether the stereoisomers would also display differences in their reinforcing effects.

Converging evidence from diverse fields, including data from behavioral studies, electrophysiological studies, and radioligand binding studies, indicates that central 5-HT systems, specifically $5-\mathrm{HT}_{2 \mathrm{~A}}$ receptors, play a major role in the mediation of hallucinogen effects (e.g. Sadzot et al. 1989). Consistent with this finding, the behavioral effects of many hallucinogen-like drugs can be blocked by $5-\mathrm{HT}_{2}$ antagonists. For example, the nonselective $5-\mathrm{HT}_{1 / 2}$ antagonists metergoline, pizotifen, and cinanserin attenuate the rate-decreasing effects of lysergic acid diethylamide (LSD) and 2,5-dimethoxy-4-methylamphetamine (DOM) on food-reinforced responding in rats (Mokler et al. 1983). Additionally, the discriminative stimulus effects of DOM, mescaline, LSD, and 5-methoxy-N,N-dimethyltryptamine (5-OMe DMT) in rats can be blocked by the $5-\mathrm{HT}_{2}$ antagonists ketanserin and pirenperone (Glennon et al. 1983.) More germane to the present research, SR $( \pm)$-MDMA-induced locomotor stimulation was attenuated by the selective $5-\mathrm{HT}_{2 \mathrm{~A}}$ antagonist MDL100907 in rats (Kehne et al. 1996), and recent human studies indicate that many of the subjective effects of orally administered SR $( \pm)$-MDMA can be attenuated by pretreatments with the serotonin selective reuptake inhibitor citalopram (Liechti et al. 2000a) and the non-selective $5-\mathrm{HT}_{2 \mathrm{~A} / 2 \mathrm{C}}$ antagonist ketanserin (Liechti et al. 2000b). However, the relationship of these locomotor and subjective effects to the reinforcing effects of MDMA is unknown. Thus, as an initial test of the hypothesis that the reinforcing effects of MDMA may also be serotonergically mediated, the effects of ketanserin and MDL100907 pretreatments on subsequent self-administration of MDMA and its stereoisomers were studied.

\section{Materials and methods}

\section{Animals}

Four adult male rhesus monkeys served as subjects in initial selfadministration experiments, and five adult rhesus monkeys (three male, two female) served as subjects in subsequent antagonist studies. All subjects weighed between 6.5 and $12 \mathrm{~kg}$ and had extensive drug self-administration histories. Animals were individually housed in $83.3 \times 76.2 \times 91.4 \mathrm{~cm}$ deep stainless steel cages. A side-mounted panel was present in each cage, equipped with a row of three stimulus lamps (red-green-red) across the top, and two response levers (one mounted under each red light.) During these studies, each animal wore a Teflon mesh jacket (Lomir, Québec, Canada) connected to a flexible stainless steel spring arm attached to the rear of the cage. Animals were fed between 10 and 12 Purina monkey chows twice per day, and water was available ad libitum. Daily fresh fruit and other treats supplemented this diet. In accordance with IACUC requirements, environmental enrichment toys were also provided on a regular rotating basis.

Subjects had been previously implanted with indwelling intravenous catheters in an internal or external jugular, femoral, or brachial vein under ketamine $(10 \mathrm{mg} / \mathrm{kg}, \mathrm{IM})$ and xylazine $(2 \mathrm{mg} / \mathrm{kg}$ IM) anesthesia. Catheters were run subcutaneously from the site of implantation to an exit site in the middle of the back. Tubing was then fed through the steel spring arm and passed to the outside rear of the cage, where it was connected to drug supplies and additional infusion lines that passed through the rollers of the infusion pump. Operation of the infusion pump delivered $1 \mathrm{ml}$ of drug solution over $5 \mathrm{~s}$.

\section{Procedure}

\section{Initial self-administration experiments}

Two 60-min experimental sessions were conducted each day: a morning session starting at 10:00 a.m. and an afternoon session starting at 4:00 p.m. The onset of each session was signaled by illumination of a red stimulus light. In the presence of this light, the tenth response on the lever beneath it resulted in the operation of the infusion pump (FR10). During the 5-s infusion duration, the red stimulus light was extinguished, the center green light was illuminated, and further lever presses had no programmed consequences. Immediately following the termination of each infusion, all stimulus lights were extinguished for a 1-min time-out period (TO $1 \mathrm{~min}$ ) during which lever presses continued to have no programmed consequences. Each TO period counted toward the total 60-min session time. 
Under baseline conditions, animals were maintained on a cocaine dose of $0.01 \mathrm{mg} / \mathrm{kg}$ per injection following the above outlined schedule requirements. To ensure that responding was being maintained by the presented drug, saline was randomly substituted for cocaine approximately every third or fourth session, usually for two consecutive sessions. Additionally, a truncated doseeffect function (consisting of the ascending limb only) for SR $( \pm)$ methamphetamine self-administration was generated as a positive control for three out of four subjects in order to develop a response baseline for a drug with, perhaps, a duration of action more similar to MDMA than cocaine. Due to health concerns unrelated to MDMA self-administration, monkey 93X3579 was removed from the study prior to the methamphetamine substitutions. MDMA and methamphetamine substitutions occurred approximately twice per week and no substitutions were made on weekends. All drug substitutions followed an ascending dose order within-drug, and at least four recovery sessions occurred between substitution trials.

\section{Antagonist experiments}

Monkeys were tested twice daily on a 130-min FR30, TO45 s session maintained by four discrete doses of IV cocaine, $\mathrm{S}(+)$ MDMA, or $\mathrm{R}(-)$-MDMA. This schedule is quite similar to that previously described by Winger et al. (1989, 1992). Each component of this multiple schedule was followed by a 10 -min blackout period during which all stimulus lights were turned off and responses had no programmed consequences. The onset of each component was signaled by the illumination of the red stimulus light. In the presence of this light, the 30th response on the lever beneath it (FR30) resulted in operation of the infusion pump. During the infusion, the red stimulus light was extinguished and the center green light was illuminated. Each component of this multiple schedule allowed a maximum of 20 self-injections, or the lapse of $25 \mathrm{~min}$. Infusions were followed by a 45 -s inter-injection time-out period (TO45 s) during which all lights were turned off and responses had no programmed consequences.

The components differed from each other in the duration of infusion pump operation. The pumps were calibrated to deliver $1 \mathrm{ml}$ of solution over a 5-s interval; thus by lengthening the infusion interval, a greater amount of solution was administered, thereby providing a higher dose per infusion. Throughout these experiments the pump durations were $0.5,1.7,5.0$ and $16.7 \mathrm{~s}$. These durations corresponded to doses of $0.001,0.003,0.01$, and $0.03 \mathrm{mg} / \mathrm{kg}$ per injection when drug reservoir supply bags were filled with a concentration of $0.01 \mathrm{mg} / \mathrm{kg}$ per ml (supply bags were made on an individual basis, dependent on the animal's weight). Two higher doses were tested by filling supply bags with a concentration of $0.1 \mathrm{mg} / \mathrm{kg}$ per $\mathrm{ml}$ (again made on an individual basis, dependent on the animal's weight). Under these conditions, the pump durations remained the same but corresponded to doses of $0.01,0.03,0.1$ and $0.3 \mathrm{mg} / \mathrm{kg}$ per injection. The overlapping doses of 0.01 and 0.03 were thus delivered at two different infusion durations, allowing a comparison of the effect of infusion duration on response rates. Four different orders of pump durations were used: an ascending order, a descending order, and two mixed orders. One of these orders was selected randomly before each cocaine or saline session; however, all results are based upon data obtained under the ascending order schedule. Saline was substituted for the baseline drug (cocaine) approximately every third session. During saline substitution sessions, saline was available during all four components and rates of responding were required to be $\leq 0.5$ responses/s, or else saline was delivered contingently on subsequent sessions until this response requirement was met. The MDMA stereoisomers were substituted for cocaine periodically, but no more often than every fourth session. MDMA substitutions and 5- $\mathrm{HT}_{2 \mathrm{~A}}$ antagonist pretreatments were always conducted under the ascending dose order. Pretreatments with the 5- $\mathrm{HT}_{2 \mathrm{~A}}$ antagonists ketanserin and MDL100907 were administered intramuscularly (IM) 15 -min prior to the start of the session.

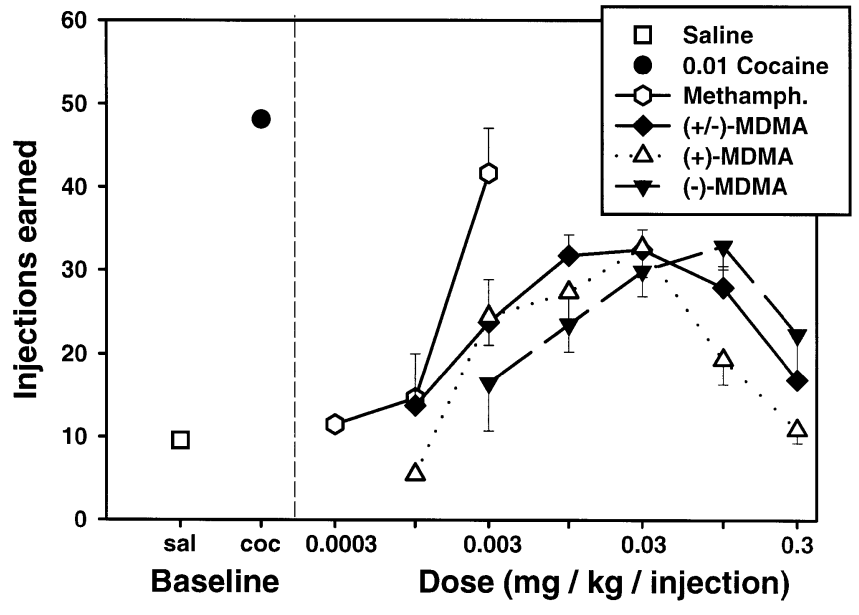

Fig. 1 Aggregated dose-response curves for MDMA and its stereoisomers in rhesus monkeys. Each point represents the mean \pm SEM ( $n=4$ for all drugs except methamphetamine, where $n=3$.) Abscissa: control responding for either $0.01 \mathrm{mg} / \mathrm{kg}$ per injection cocaine (circles) or equivolume saline (squares), or substitution responding for various doses ( $\mathrm{mg} / \mathrm{kg}$ per injection) of MDMA or methamphetamine drug solution. Ordinate: number of self-injections earned

Data analysis

In the initial self-administration studies, mean number of injections earned of each dose of each substitution drug were compared to number of earned saline and cocaine injections by paired samples $t$-tests using SPSS for Microsoft Windows, version 10.1 (SPSS, Inc., Chicago, Ill., USA). In subsequent antagonist studies, mean response rates for each dose of self-administered drug with and without antagonist pretreatment were compared by one-way ANOVA and Tukey's HSD post-hoc tests using the same statistical software as above.

\section{Drugs}

Cocaine hydrochloride, $\mathrm{SR}( \pm)$-methamphetamine, racemic MDMA and its stereoisomers were supplied by the National Institute on Drug Abuse (Research Technology Branch, Research Triangle Park, N.C., USA). All of these drugs were weighed as salts and dissolved in physiological saline prior to injection. Ketanserin tartrate was purchased from Research Biochemicals International (Natick, Mass., USA), weighed as the free base, and dissolved in sterile water and 5\% DMSO. MDL100907 was synthesized at the Laboratory of Medicinal Chemistry at the National Institutes of Diabetes, Digestive and Kidney Disorders at the National Institutes of Health (Bethesda, Md., USA), and dissolved in sterile water and $0.5 \mathrm{~N} \mathrm{HCl}$.

\section{Results}

Initial self-administration experiments

Number of injections earned of MDMA across a dose range of $0.001,0.003,0.01,0.03,0.1$, and $0.3 \mathrm{mg} / \mathrm{kg}$ per injection were compared to number of self-injections earned of cocaine, methamphetamine and saline. These MDMA doses were chosen based on a previous study of MDMA self-administration in rhesus monkeys (Beardsley et al. 1986). To aggregate data across all four experimental animals, mean numbers of injections earned by each 

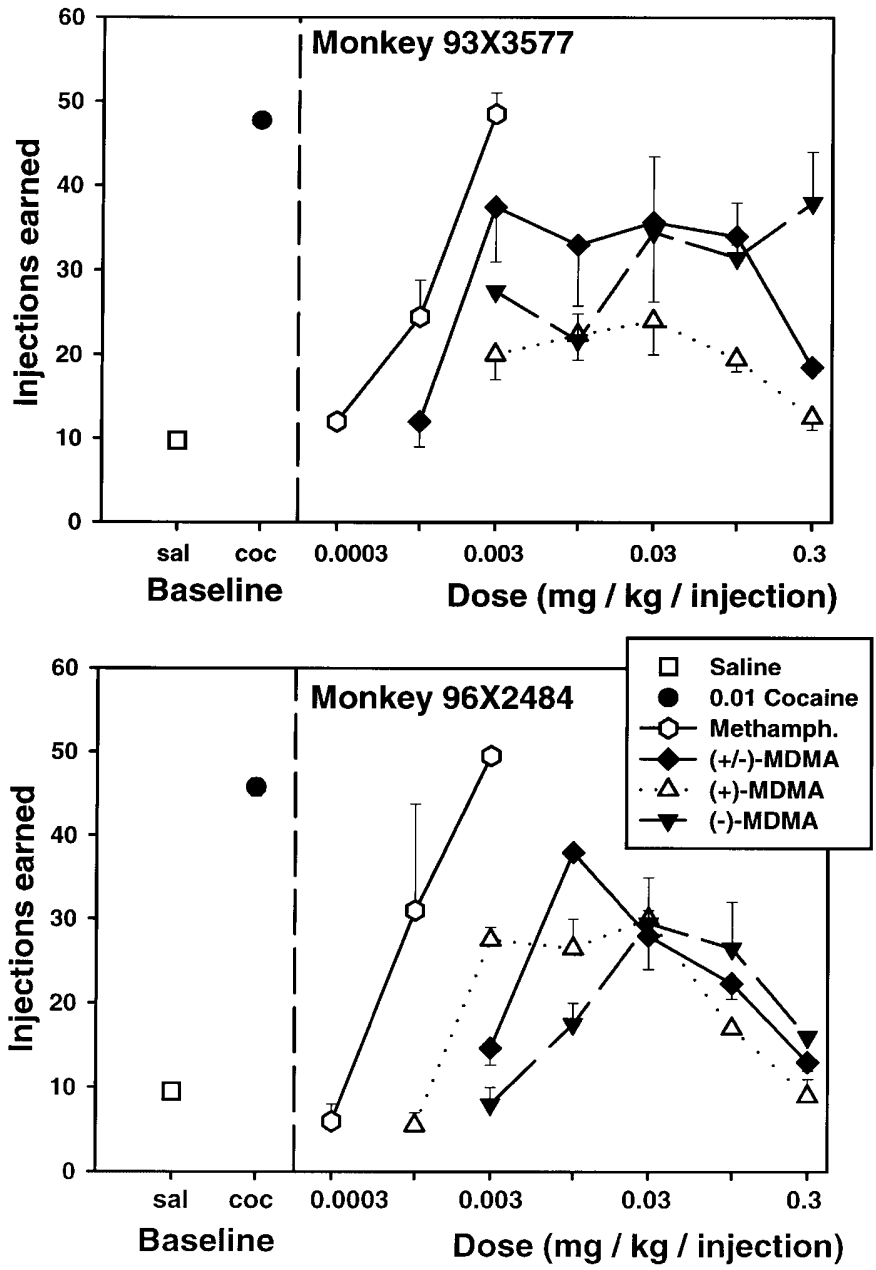

Fig. 2 Individual dose-response curves for MDMA and its stereoisomers in rhesus monkeys. Each point represents the mean \pm SEM ( $n=3$ or 4 observations per dose). Abscissae: as described in Fig. 1. Ordinates: number of self-injections earned

monkey at each dose were averaged. Because there was no pre-session stimulus change or priming injection to predict which solution was available to the animal for self-injection, a small amount of "sampling" occurred at the beginning of each saline session but generally abated within ten infusions. Figure 1 presents the aggregate dose-response curves for methamphetamine, racemic MDMA, and both stereoisomers. All animals self-administered racemic MDMA and the stereoisomers.

The truncated dose-response curve for methamphetamine shows that a drug with an extended duration of action can maintain an equal number of injections as cocaine under this schedule. Responding maintained by $0.003 \mathrm{mg} / \mathrm{kg}$ per injection methamphetamine was significantly different from that maintained by saline $(t=-5.936$, $d f=2, P<0.05$ ), but not significantly different from that maintained by $0.01 \mathrm{mg} / \mathrm{kg}$ per injection cocaine. Racemic MDMA and both enantiomers generated inverted U-shaped functions across the dose ranges tested. For SR( \pm )-MDMA, doses of 0.01 ( $t=-8.141, d f=3, P<0.01), 0.03(t=-11.165$, $d f=3, P<0.01)$, and $0.1(t=-7.592, d f=3, P<0.01) \mathrm{mg} / \mathrm{kg}$
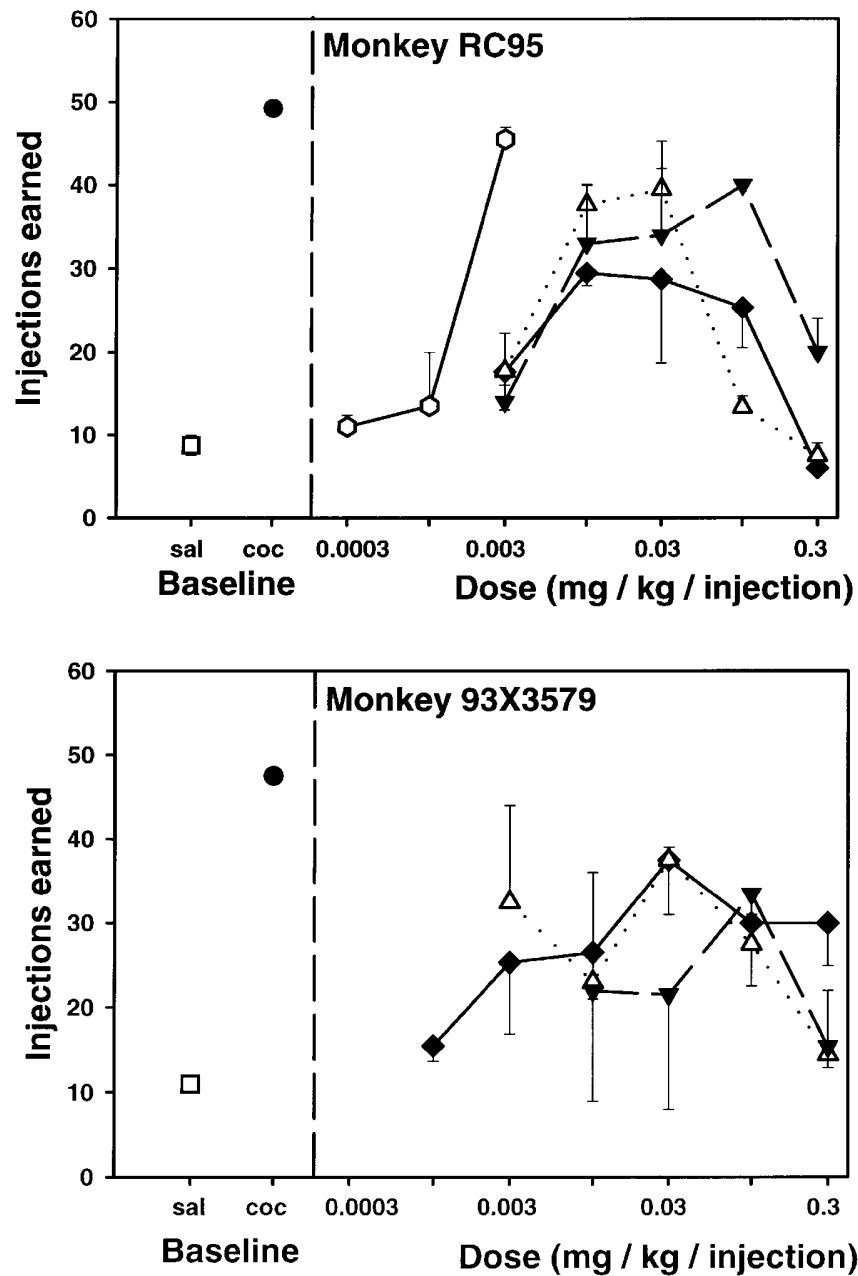

per injection engendered significantly more injections than saline. For S(+)-MDMA, doses of $0.003(t=-4.864$, $d f=3, \quad P<0.05), \quad 0.01 \quad(t=-4.488, \quad d f=3, \quad P<0.05), \quad 0.03$ $(t=-6.397, d f=3, P<0.01)$ and $0.1(t=-3.777, d f=3, P<0.05)$ $\mathrm{mg} / \mathrm{kg}$ per injection engendered significantly more injections than saline. Finally, for R(-)-MDMA, doses of 0.01 $(t=-3.847, d f=3, P<0.05), 0.03 \quad(t=-5.885, d f=3, P<0.05)$ and $0.1 \quad(t=-7.788, d f=3, P<0.01) \mathrm{mg} / \mathrm{kg}$ per injection engendered significantly more injections than saline. No dose of any of the MDMA compounds maintained as many injections as $0.01 \mathrm{mg} / \mathrm{kg}$ per injection cocaine or $0.003 \mathrm{mg} / \mathrm{kg}$ per injection methamphetamine.

Interestingly, there was no marked difference in the maximum number of injections earned by animals receiving racemic MDMA or the stereoisomers. Responding maintained by SR( \pm )-MDMA, S(+)-MDMA, and R(-)-MDMA all peaked at approximately 35 injections. Although the doses at which the three MDMA compounds maintained peak responding appeared to differ (Fig. 1), no consistent potency order could be obtained from the individual subject data. Figure 2 presents the dose-response curves for methamphetamine, racemic MDMA, and both stereoisomers for monkeys RC95, 93X3577, 93X3579, and 96X2484, respectively. No individual animal is well represented by the aggregate group data. 
Table 1 Peak response rates (responses/s), and doses $(\mathrm{mg} / \mathrm{kg}$ per injection) that engender these maximal rates, for cocaine, S(+)-MDMA and R(-)-MDMA for each monkey. Failures to self-administer at rates greater than those engendered by contingent saline $(<0.3$ responses/s) are indicated by $n / a$

\begin{tabular}{|c|c|c|c|c|c|c|}
\hline \multirow[b]{2}{*}{ Monkey } & \multicolumn{2}{|c|}{ Cocaine } & \multicolumn{2}{|c|}{ (+)-MDMA } & \multicolumn{2}{|c|}{ (-)-MDMA } \\
\hline & Rate & Dose & Rate & Dose & Rate & Dose \\
\hline $92 \times 2643$ & 3.43 & 0.01 & 1.00 & 0.03 & 1.00 & 0.03 \\
\hline $98 \times 3152$ & 1.48 & 0.01 & 1.28 & 0.03 & 0.77 & 0.01 \\
\hline $94 \times 0352$ & 1.74 & 0.10 & 1.04 & 0.03 & 1.66 & 0.10 \\
\hline $96 \times 4394$ & 3.58 & 0.03 & 1.90 & 0.03 & $\mathrm{n} / \mathrm{a}$ & $\mathrm{n} / \mathrm{a}$ \\
\hline $95 \times 2739$ & 1.98 & 0.01 & $\mathrm{n} / \mathrm{a}$ & $\mathrm{n} / \mathrm{a}$ & 1.05 & 0.03 \\
\hline
\end{tabular}

Antagonist experiments

Response rates (responses/s) for cocaine, racemic MDMA and its stereoisomers across a dose range of $0.001,0.003$, $0.01,0.03,0.1$, and $0.3 \mathrm{mg} / \mathrm{kg}$ per injection, with and without $5-\mathrm{HT}_{2 \mathrm{~A}}$ antagonist pretreatment, were assessed. To aggregate data across all five experimental animals, mean response rates engendered by each dose of each drug were averaged. There was considerable variability across animals, both in terms of which dose engendered peak responding and in terms of absolute peak response rate. These data are summarized in Table 1 below.

Under this multiple component schedule, contingent saline infusions engendered very low response rates (less than 0.3 responses/s). As in the initial self-administration experiments, there was no pre-session stimulus change or priming injection to predict which solution was available to the animal for self-injection. The small amount of "sampling" occurring at the beginning of each saline session generally abated quickly. Figure 3 presents the aggregate dose-response curves for cocaine at baseline conditions and following pretreatments with ketanserin or MDL100907. All animals self-administered cocaine within the dose range tested and showed inverted U-shaped functions. With dose held constant, infusion duration did not affect rates of self-administration. Response rates engendered by cocaine doses of 0.01 and $0.03 \mathrm{mg} / \mathrm{kg}$ per injection delivered at long infusion durations $(5.0$ and $16.7 \mathrm{~s})$ were not different from rates engendered when these doses were delivered at short infusion durations $(0.5$ and $1.7 \mathrm{~s})$.

Ketanserin pretreatments had little effect on the cocaine dose-effect curve (Fig. 3, top panel). The ascending limb of the curve was shifted slightly rightwards; however, this effect was not dose-dependent or statistically significant, and was highly variable among animals. The descending limb of the cocaine dose-effect curve was not affected by ketanserin pretreatment. Pretreatments with MDL100907 produced a similar effect on cocaine-maintained responding to that observed with ketanserin (Fig. 3, bottom panel). However, a downward shift in the cocaine dose-effect curve was produced following pretreatment with the highest dose of MDL100907 tested $(1 \mathrm{mg} / \mathrm{kg})$. Although this was a
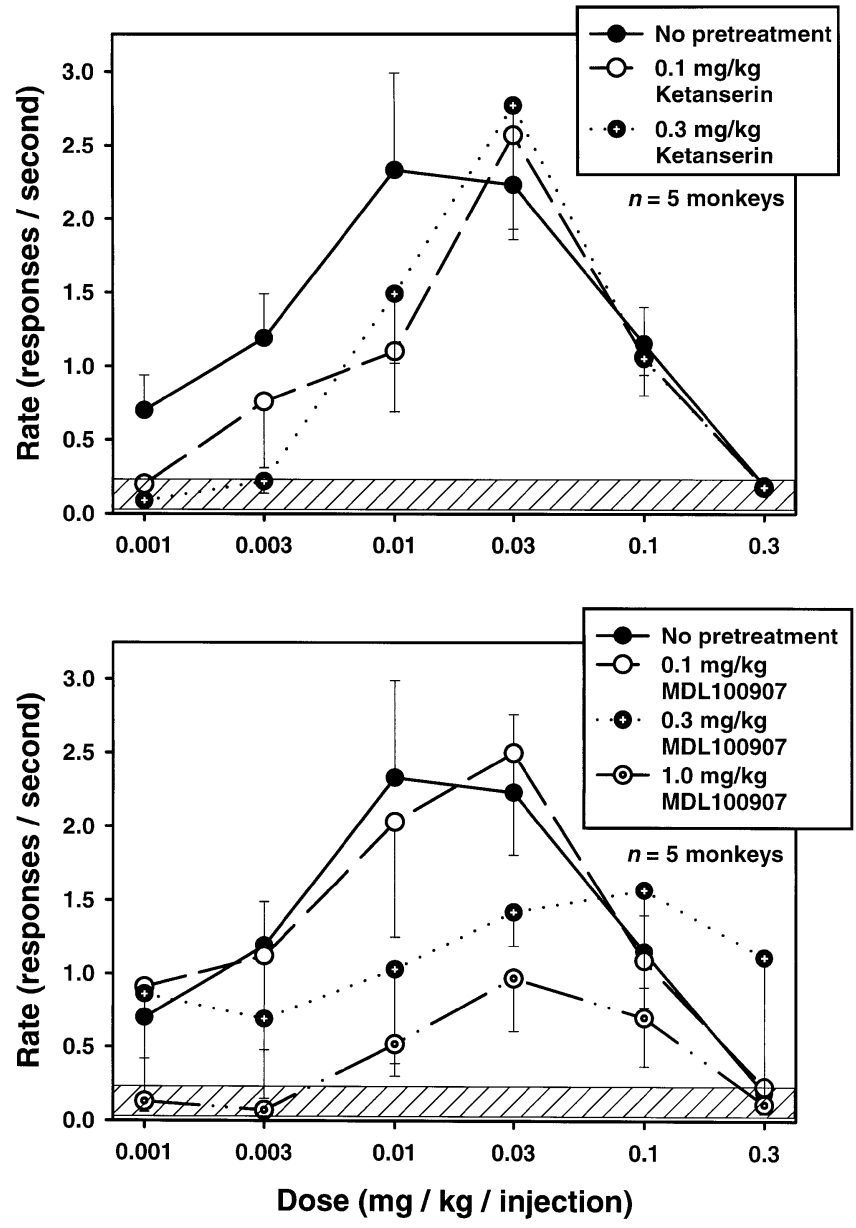

Fig. 3 Aggregated dose-response curves for cocaine with and without $5-\mathrm{HT}_{2 \mathrm{~A}}$ antagonist pretreatment. Each point represents the mean \pm SEM $(n=5)$. Abscissa: dose of self-administered drug $(\mathrm{mg} / \mathrm{kg}$ per injection). Ordinate: response rate (responses/s). Stippled region represents the range of response rates engendered by contingent saline

large and dose-related effect, the variability among animals in baseline response rates precluded achievement of statistical significance.

As in the initial self-administration experiments, (+)MDMA generated an inverted U-shaped function across the dose range tested (Fig. 4). Self-administration behavior was more variable under this multiple schedule however, and one animal did not self-administer this isomer at rates significantly greater than those engendered by contingent saline. Figure 4 presents the aggregate doseresponse curves for (+)-MDMA at baseline conditions and following pretreatment with ketanserin (top panel) or MDL100907 (bottom panel).

Ketanserin pretreatments shifted the entire (+)MDMA dose-effect curve downwards. There was no dose-dependent effect of ketanserin on (+)-MDMAmaintained behavior; 0.1 and $0.3 \mathrm{mg} / \mathrm{kg}$ ketanserin produced an equivalent, but non-significant, suppression of (+)-MDMA-maintained responding. Interestingly, MDL100907 produced a right-shift on the ascending limb of the (+)-MDMA self-administration curve similar 

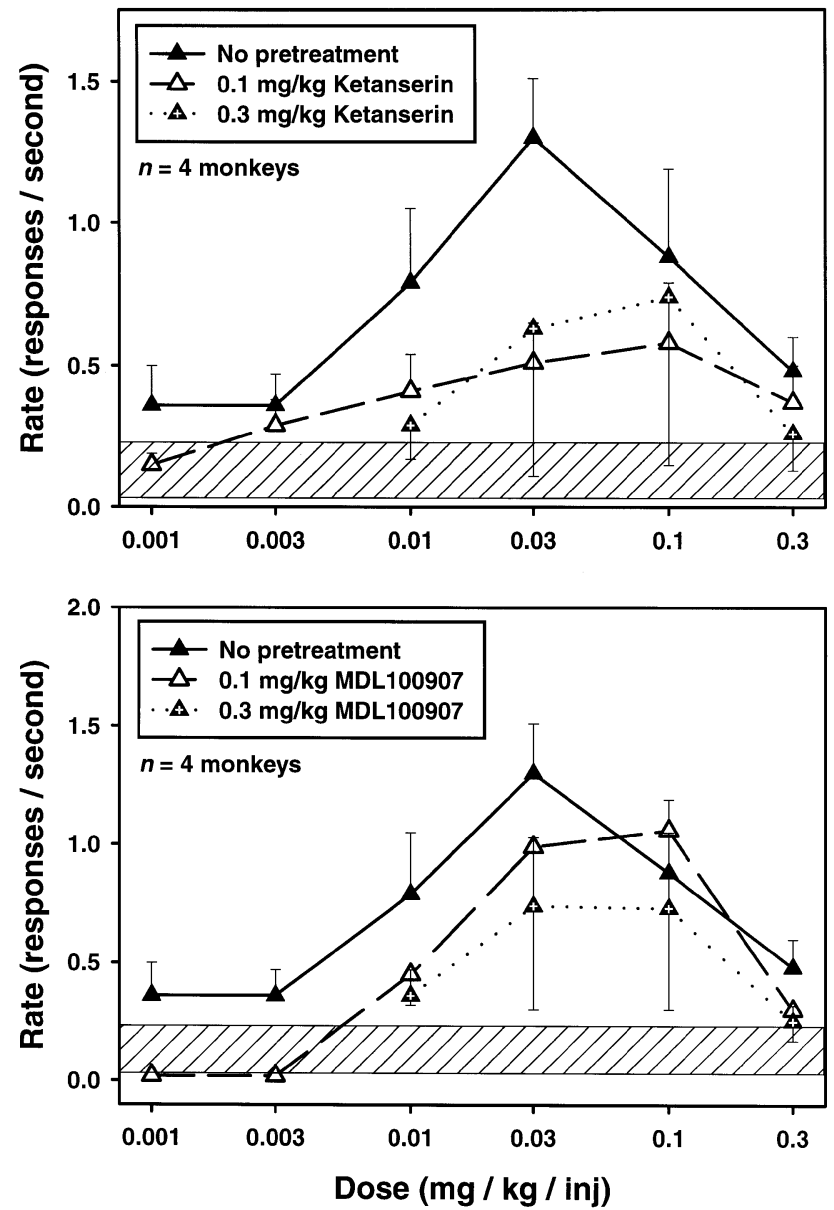

Fig. 4 Aggregated dose-response curves for S(+)-MDMA with and without $5-\mathrm{HT}_{2 \mathrm{~A}}$ antagonist pretreatment. Each point represents the mean \pm SEM $(n=4)$. Abscissa: dose of self-administered drug $(\mathrm{mg} / \mathrm{kg}$ per injection). Ordinate: response rate (responses/s). Stippled region represents the range of response rates engendered by contingent saline

to that observed with cocaine. As with self-administered cocaine, this effect was not dose-dependent or statistically significant, and the descending limb of the (+)-MDMA dose-effect curve was relatively insensitive to MDL100907 pretreatments.

Similar to the initial self-administration experiments, $(-)$-MDMA generated an inverted U-shaped function across the dose range tested (Fig. 5). As with (+)MDMA, self-administration behavior was more variable under this multiple-component procedure, and one animal did not self-administer (-)-MDMA at rates significantly greater than those engendered by contingent saline. Figure 5 presents the aggregate dose-response curves for (-)-MDMA at baseline conditions and following pretreatment with ketanserin or MDL100907.

Pretreatments with $0.1 \mathrm{mg} / \mathrm{kg}$ ketanserin completely suppressed responding for all but the highest dose of (-)MDMA. Due to the high variability of baseline response rates for (-)-MDMA among monkeys, this effect reached statistical significance only at $0.03 \mathrm{mg} / \mathrm{kg}$ per injection $(-)$-MDMA $[F(1,6)=9.086, P<0.05]$, although the antag-
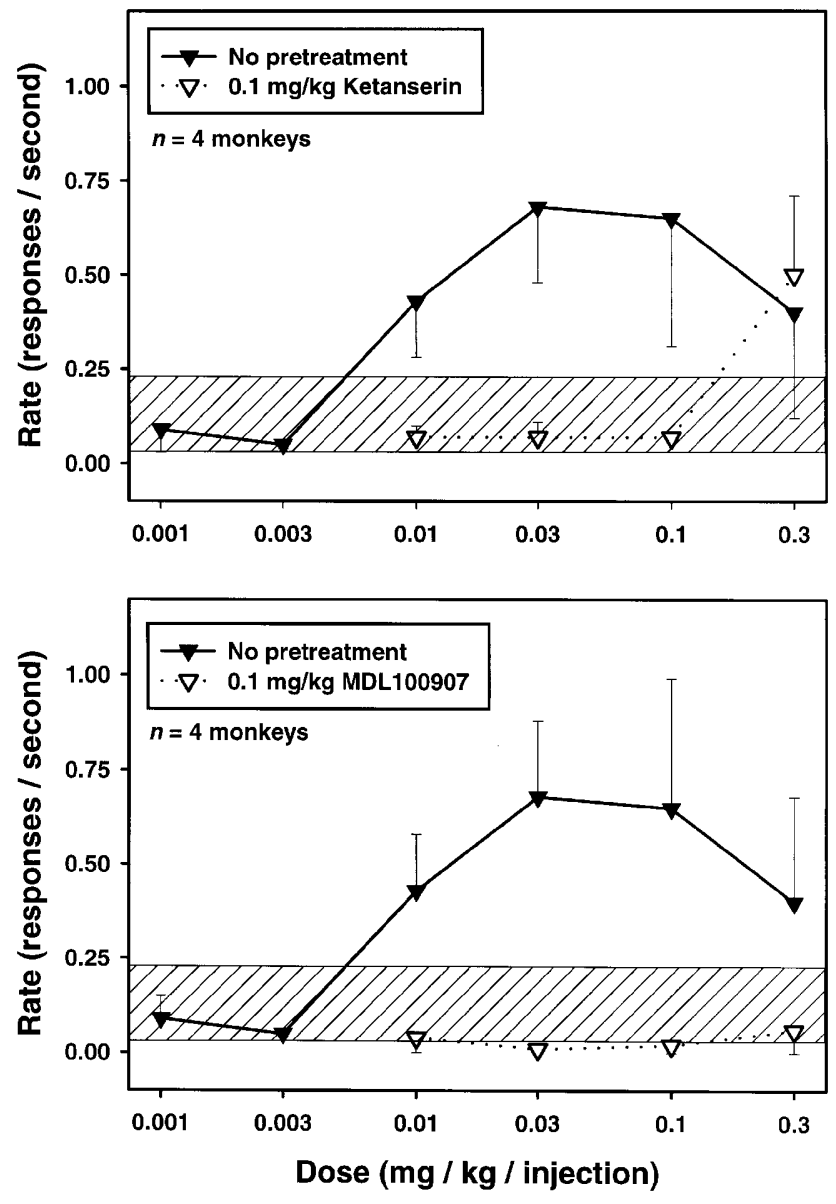

Fig. 5 Aggregated dose-response curves for R(-)-MDMA with and without $5-\mathrm{HT}_{2 \mathrm{~A}}$ antagonist pretreatment. Each point represents the mean \pm SEM ( $n=4)$. Abscissa: dose of self-administered drug (mg/kg per injection). Ordinate: response rate (responses/s). Stippled region represents the range of response rates engendered by contingent saline

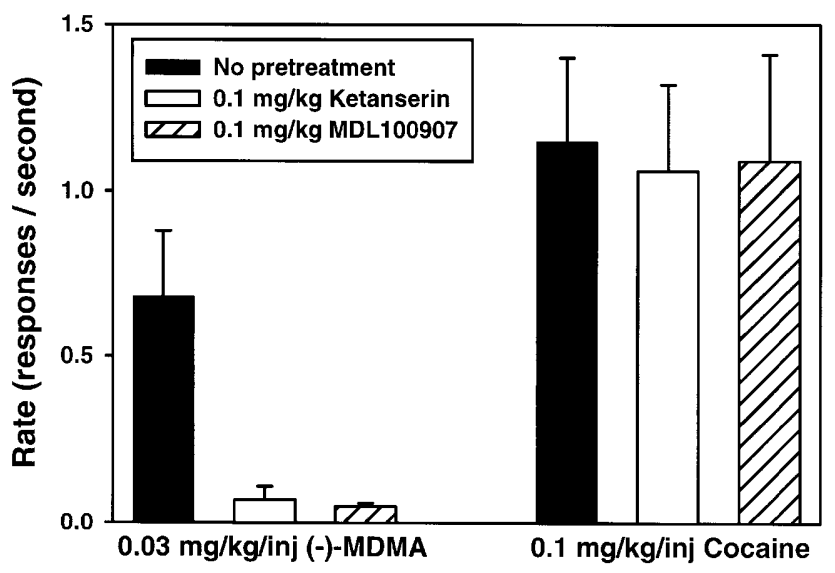

Fig. 6 Rate-matched doses of cocaine and R(-)-MDMA with and without $5-\mathrm{HT}_{2 \mathrm{~A}}$ antagonist pretreatment. Each bar represents the mean \pm SEM $(n=4)$. Abscissae: self-administered drug and dose (mg/kg per injection). Ordinates: response rate (responses/s) 
onism observed at $0.01 \mathrm{mg} / \mathrm{kg}$ per injection was nearly significant $[F(1,6)=5.407, P=0.059]$. Pretreatments with $0.1 \mathrm{mg} / \mathrm{kg}$ MDL100907 completely abolished responding for all doses of (-)-MDMA. This effect was significant at $0.03 \mathrm{mg} / \mathrm{kg}$ per injection $(-)$-MDMA $[F(1,6)=9.594$, $P<0.05$ ], although the antagonism observed at 0.01 was also close to the significance threshold $[F(1,6)=4.915$, $P=0.068]$. The pretreatment dose of $0.1 \mathrm{mg} / \mathrm{kg}$ was the lowest dose tested for each of the antagonists, and neither ketanserin nor MDL100907 affected cocainemaintained behavior at this dose. Figure 6 presents ratematched responding for each animal that reliably selfadministered $\mathrm{R}(-)$-MDMA: doses of cocaine and $\mathrm{R}(-)$ MDMA that engendered equivalent response rates were thus compared with and without $5-\mathrm{HT}_{2 \mathrm{~A}}$ antagonist pretreatments. The antagonists selectively attenuated responding maintained by $\mathrm{R}(-)$-MDMA, indicating that the effect was not rate-dependent under the present conditions.

\section{Discussion}

Studies on the reinforcing effects of serotonergic drugs have thus far yielded scant evidence to implicate this neurotransmitter system in reward function. Indeed, drugs with serotonergic mechanisms of action have only rarely been shown to maintain significant self-administration behavior. One of the earliest studies of intravenous drug self-administration in rhesus monkeys assessed the reinforcing properties of the hallucinogenic phenethylamine mescaline and found that no animal initiated self-injection of this 5-HT agonist either spontaneously or after 1 month of programmed administration (Deneau et al. 1969). Similarly, the phenylisopropylamine hallucinogen DOM also failed to maintain self-administration in rhesus (Yanagita 1986) and squirrel monkeys, as did the serotonin-selective reuptake inhibitors (SSRIs) alaproclate, clomipramine, and fluoxetine (Howell and Byrd 1996). Finally, and most intriguing given the present results, the 5-HT releaser fenfluramine failed to maintain self-administration behavior in rhesus monkeys (Woods and Tessel 1974), despite the fact that its proposed primary mechanism of action (5-HT release) is shared by MDMA. To our knowledge, MDMA, MDA and MDE (Griffiths et al. 1976; Beardsley et al. 1986; Lamb and Griffiths 1987; Sannerud et al. 1996) were the only hallucinogen-like drugs that maintained responding in primate IV self-administration paradigms. The reinforcing effects of other methylenedioxy analogues of amphetamine (e.g. MTA, MMAI, MBDB) therefore deserve further study in self-administration experiments in primates.

Despite the failures of serotonergic drugs to maintain responding in self-administration paradigms, a growing body of literature has begun to describe a complex serotonergic involvement in reward mechanisms. Depletion and lesion studies have shown that decreased 5-HT levels were associated with increased DA activity in several brain areas implicated in reward functions, including the ventral tegmental area and the nucleus accumbens (White et al. 1995; Morgan et al. 1997). Additionally, destruction of 5-HT neurons with 5,7-DHT increased self-administration of $d$-amphetamine in rats (Lyness et al. 1980). Nonetheless, other studies have shown no change in the rewarding threshold for electrical stimulation of the brain following 5-HT manipulation (Lin et al. 1997). More germane to the present research, it has been shown that $\mathrm{SR}( \pm)$-MDMA-induced dopamine release can be potentiated in rats receiving pretreatments with $5-\mathrm{HT}_{2}$ receptor agonists DOI and 5-OMe DMT (Gudelsky et al. 1994), and reduced in rats receiving pretreatments with 5- $\mathrm{HT}_{2}$ receptor antagonists MDL 100907 and amperozide (Schmidt et al. 1994). However, because R(-)-MDMA had much less of an increasing effect than S(+)-MDMA on DA levels in striatal dialysate (Hiramatsu and Cho 1990), the applicability of these results across MDMA enantiomers is questionable. Indeed, given the comparable lack of dopaminergic effects, the finding that $\mathrm{R}(-)$ MDMA was self-administered at all was somewhat surprising.

The amount of variability in MDMA-maintained behavior was much greater than that obtained when cocaine was available for self-administration, leading to pronounced individual differences in MDMA selfinjection. Analogous individual differences in primate self-administration have been documented previously in experiments involving oral ethanol intake (Vivian et al. 1999) and have been correlated with endogenous 5-HT levels (Higley and Bennett 1999). Similar factors may underlie the presently reported individual differences in MDMA self-administration.

The effects of the 5- $\mathrm{HT}_{2 \mathrm{~A}}$ antagonists on MDMAmaintained responding raise several intriguing issues, especially in light of the fact that several studies have indicated that stimulation of the $5-\mathrm{HT}_{2 \mathrm{~A}}$ receptor alone is not sufficient to maintain self-administration behavior. First, previous studies have shown that DOM (a 5- $\mathrm{HT}_{2 \mathrm{~A}}$ agonist) was not intravenously self-administered by rhesus (Yanagita 1986) or squirrel monkeys (Howell and Byrd 1995). Second, in the present studies, antagonism of the $5-\mathrm{HT}_{2 \mathrm{~A}}$ receptor did not consistently affect cocaine-maintained responding. However, blockade of this receptor by ketanserin and MDL100907 clearly attenuated S(+)-MDMA self-administration and almost completely abolished the reinforcing effects of R(-)-MDMA. In this regard, it is possible that the $5-\mathrm{HT}_{2 \mathrm{~A}}$ receptors stimulated by agonists such as DOM are distinct from those activated by endogenous 5-HT released by MDMA. An alternative explanation is that $\mathrm{S}(+)-$ and $\mathrm{R}(-)-$ MDMA reinforcement is dependent on the $5-\mathrm{HT}_{2 \mathrm{~A}}$ receptor, while cocaine reinforcement is not. The selfadministration literature does provide some evidence that cocaine-maintained behavior may be less sensitive to manipulations of the serotonin system than is behavior maintained by amphetamine-like drugs. For example, pretreatments with fluoxetine and cinanserin both decreased rates of amphetamine-maintained responding 
in rats at doses that did not affect cocaine-maintained behavior (Porrino et al. 1989). However, recent evidence has shown that $5-\mathrm{HT}_{2 \mathrm{~A}}$ antagonists attenuate the motor stimulant and discriminative stimulus properties of cocaine in rats (McMahon and Cunningham 2001). Why these antagonistic actions did not seem to extend to the reinforcing effects of cocaine in the present study is unclear.

The data presented in this report provide evidence that MDMA and its stereoisomers are effective reinforcers in rhesus monkeys. The antagonist studies suggest that the reinforcing effects of the MDMA stereoisomers are distinct from those of cocaine. Further, we suggest that the 5-HT system, specifically stimulation of the $5-\mathrm{HT}_{2 \mathrm{~A}}$ receptor, is integral to the reinforcing effects MDMA. The possibility that the reinforcing effects of methylenedioxy amphetamine derivatives may be mediated through a novel serotonergic reward mechanism deserves further study.

Acknowledgements These studies were supported by USPHS Grants DA09161 and DA05923. The authors express their gratitude for the expert technical assistance provided by Amy Foster, Deborah Huntzinger, Sarah Pilkington, and Jolan Terner.

\section{References}

Baker L, Taylor M (1997) Assessment of the MDA and MDMA optical isomers in a stimulant-hallucinogen discrimination. Pharmacol Biochem Behav 57:737-748

Baker L, Broadbent J, Michael E, Matthews C, Metosh R, West W, Appel J (1995) Assessment of the discriminative stimulus effects of the optical isomers of ecstasy (3,4-methylenedioxymethamphetamine; MDMA). Behav Pharmacol 6:263-275

Battaglia G, DeSouza E (1989) Pharmacologic profile of amphetamine derivatives at various brain recognition sites: selective effects on serotonin systems. NIDA Res Monogr 94:240-258

Battaglia G, Yeh S, O'Hearn E, Molliver M, Kuhar M, DeSouza E (1987) 3,4-Methylenedioxymethamphetamine and 3,4-methylenedioxyamphetamine destroy serotonin nerve terminals in rat brain: quantification of neurodegeneration by measurement of $\left[{ }^{3} \mathrm{H}\right]$-paroxetine-labeled serotonin uptake sites. J Pharmacol Exp Ther 242:911-916

Battaglia G, Brooks B, Kulsakdinum C, DeSouza E (1988a) Pharmacologic profile of MDMA (3,4-methylenedioxymethamphetamine) at various brain recognition sites. Eur J Pharmacol 149:159-163

Battaglia G, Yeh S, DeSouza E (1988b) MDMA-induced neurotoxicity: parameters of degeneration and recovery of brain serotonin neurons. Pharmacol Biochem Behav 29:269-274

Beardsley P, Balster R, Harris L (1986) Self-administration of methylenedioxymethamphetamine (MDMA) by rhesus monkeys. Drug Alcohol Depend 18:149-157

Bilsky E, Hui Y, Hubbell C, Reid L (1991) Methylenedioxymethamphetamine's capacity to establish place preference and modify intake of an alcoholic beverage. Pharmacol Biochem Behav 37:633-638

Brown E, Jarbie D, Simpson D (1995) Use of drugs at "raves." Scot Med J 40:168-171

Deneau G, Yanagita T, Seevers M (1969) Self-administration of psychoactive substances by the monkey - a measure of psychological dependence. Psychopharmacologia 16:30-48

Glennon R, Young R, Rosecrans J (1983) Antagonism of the effects of the hallucinogen DOM and the purported 5-HT agonist quipazine by $5-\mathrm{HT}_{2}$ antagonists. Eur J Pharmacol 3:289-340
Glennon R, Yousif M, Patrick G (1988) Stimulus properties of 1-(3,4-methylenedioxyphenyl)-2-aminopropane (MDA) analogs. Pharmacol Biochem Behav 29:443-449

Griffiths R, Winger G, Brady J, Snell J (1976) Comparison of behavior maintained by infusions of eight phenylethylamines in baboons. Psychopharmacology 50:251-258

Gudelsky G, Yamamoto B, Nash J (1994) Potentiation of 3,4methylenedioxymethamphetamine-induced dopamine release and serotonin neurotoxicity by $5-\mathrm{HT}_{2}$ receptor agonists. Eur $\mathrm{J}$ Pharmacol 246:325-330

Hatzidimitriou G, McCann U, Ricaurte G (1999) Altered serotonin innervation patterns in the forebrain of monkeys treated with ( \pm )-3,4-methylenedioxymethamphetamine seven years previously: factors influencing abnormal recovery. J Neurosci 19:5096-5107

Higley J, Bennett J (1999) Central nervous system serotonin and personality as variables contributing to excessive alcohol consumption in non-human primates. Alcohol Alcohol 34: 402-418

Hiramatsu M, Cho AK (1990) Enantiomeric differences in the effects of 3,4-methylenedioxymethamphetamine on extracellular monoamines and metabolites in the striatum of freely-moving rats: an in vivo microdialysis study. Neuropharmacology 29: 269-275

Howell L, Byrd L (1995) Serotonergic modulation of the behavioral effects of cocaine in the squirrel monkey. J Pharmacol Exp Ther 275:1551-1559

Hubner C, Bird M, Rassnick S, Kornetsky C (1988) The threshold lowering effects of MDMA (ecstasy) on brain-stimulation reward. Psychopharmacology 95:49-51

Kehne J, Ketteler H, McCloskey T, Sullivan C, Dudley M, Schmidt C (1996) Effects of the selective 5- $\mathrm{HT}_{2 \mathrm{~A}}$ receptor antagonist MDL 100,907 on MDMA-induced locomotor stimulation in rats. Neuropsychopharmacology 15:116-124

Lamb R, Griffiths R (1987) Self-injection of d,1-3,4-methylenedioxymethamphetamine (MDMA) in the baboon. Psychopharmacology 91:268-272

Liechti M, Baumann C, Gamma A, Vollenweider F (2000a) Acute psychological effects of 3,4-methylenedioxymethamphetamine (MDMA, "ecstasy") are attenuated by the serotonin uptake inhibitor citalopram. Neuropsychopharmacology 22:513-521

Liechti M, Saur M, Gamma A, Hell D, Vollenweider F (2000b) Psychological and physiological effects of MDMA ("ecstasy") after pretreatment with the 5-HT(2) antagonist ketanserin in healthy humans. Neuropsychopharmacology 23:396-404

Lin H, Jackson D, Atrens D, Christie M, McGregor I (1997) Serotonergic modulation of 3,4-methylenedioxymethamphetamine (MDMA)-elicited reduction of response rate but not rewarding threshold in accumbal self-stimulation. Brain Res 744:351-357

Lyness W, Friedle N, Moore K (1980) Increased self-administration of $d$-amphetamine after destruction of 5-hydroxytryptaminergic neurons. Pharmacol Biochem Behav 18:721-724

Marona-Lewicka D, Rhee G, Sprague J, Nichols D (1996) Reinforcing effects of certain serotonin-releasing amphetamine derivatives. Pharmacol Biochem Behav 53:99-105

McMahon L, Cunningham K (2001) Antagonism of 5-hydroxytryptamine $_{2 \mathrm{~A}}$ receptors attenuates the behavioral effects of cocaine in rats. J Pharmacol Exp Ther 297:357-363

Mokler D, Commissaris R, Warner M, Rech R (1983) Blockade of the behavioral effects of lysergic acid diethylamide, 2,5dimethoxy-4-methylamphetamine, quipazine and lisuride by 5-hydroxytryptamine antagonists. J Pharmacol Exp Ther 227: $557-562$

Morgan A, Horan B, Dewey S, Ashby C (1997) Repeated administration of 3,4-methylenedioxymethamphetamine augments cocaine's action on dopamine in the nucleus accumbens: a microdialysis study. Eur J Pharmacol 331:R1-R3

Nichols D, Oberlender R (1990) Structure-activity relationships of MDMA and related compounds: a new class of psychoactive agents? In: Peroutka S (ed) Ecstasy: the clinical, pharmacological, and neurotoxicological effects of the drug MDMA. Kluwer, Boston, pp 153-162 
Porrino L, Ritz M, Goodman N, Sharpe L, Kuhar M, Goldberg S (1989) Differential effects of the pharmacological manipulation of serotonin systems on cocaine and amphetamine self-administration in rats. Life Sci 45:1529-1535

Ricaurte G, Martello A, Katz J, Martello M (1992) Lasting effects of ( \pm )-3,4-methylenedioxymethamphetamine (MDMA) on central serotonergic neurons in nonhuman primates: neurochemical observations. J Pharmacol Exp Ther 261: 616-622

Rudnick G, Wall S (1992) The molecular mechanism of [3,4-methylenedioxy-methamphetamine (MDMA)]: serotonin transporters are targets for MDMA-induced serotonin release. Proc Natl Acad Sci USA 89:1817-1821

Sadzot B, Baraban J, Glennon R, Lyon R, Leonhardt S, Jan C, Titeler M (1989) Hallucinogenic drug interactions at human brain 5-HT $\mathrm{H}_{2}$ receptors: implications for treating LSD-induced hallucinogenesis. Psychopharmacology 98:495-499

Sannerud C, Kaminski B, Griffiths R (1996) Intravenous selfinjection of four novel phenethylamines in baboons. Behav Pharmacol 7:315-323

Schmidt C, Sullivan C, Fadayel G (1994) Blockade of striatal 5 -hydroxytryptamine, receptors reduces the increase in extracellular concentrations of dopamine produced by the amphetamine analogue 3,4-methylenedioxymethamphetamine. J Neurochem 62:1382-1389

Vivian J, Higley J, Linnoila M, Woods J (1999) Oral ethanol selfadministration in rhesus monkeys: behavioral and neurochemical correlates. Alcohol Clin Exp Res 23:1352-1361

White S, Harris G, Imel K, Wheaton M (1995) Inhibitory effects of dopamine and methylenedioxymethamphetamine (MDMA) on glutamate-evoked firing of nucleus accumbens and caudate/ putamen cells are enhanced following cocaine self-administration. Brain Res 681:167-176

Winger G, Palmer R, Woods J (1989) Drug-reinforced responding: rapid determination of dose-response functions. Drug Alcohol Depend 24:135-142

Winger G, Skjoldager P, Woods J (1992) Effects of buprenorphine and other opioid agonists and antagonists on alfentanil- and cocaine-reinforced responding in rhesus monkeys. J Pharmacol Exp Ther 261:311-317

Woods J, Tessel R (1974) Fenfluramine: amphetamine congener that fails to maintain drug-taking behavior in the rhesus monkey. Science 185:1067-1069

Yanagita T (1986) Intravenous self-administration of R(-)-cathinone and 2-amino-1-(2,5-dimethoxy-4-methyl) phenylpropane in rhesus monkeys. Drug Alcohol Depend 17:135-141 